\title{
Interconnecting Single-Phase Backup Generation to the Utility Distribution System
}

\author{
Roger C. Dugan, Fellow, IEEE, Thomas E. McDermott, Senior Member, IEEE, \\ D. T. Rizy, Senior Member, IEEE, and Stephen J. Steffel
}

\begin{abstract}
One potentially large source of underutilized distributed generation (DG) capacity exists in single-phase standby backup gensets on farms served from single-phase feeder laterals. Utilizing the excess capacity would require interconnecting to the utility system. Connecting single-phase gensets to the utility system presents some interesting technical issues that have not been previously investigated. This paper addresses several of the interconnection issues associated with this form of DG including voltage regulation, harmonics, overcurrent protection, and islanding. A significant amount of single-phase DG can be accommodated by the utility distribution system, but there are definite limitations due to the nature and location of the DG. These limitations may be more restrictive than is commonly assumed for three-phase DG installed on stronger parts of the electric distribution system.
\end{abstract}

Index Terms--Distributed generation, Power distribution, Power system harmonics, Power system protection.

\section{INTRODUCTION}

$\mathrm{D}$ uring the summer of 1999 the Delmarva Peninsula, a service territory including Delaware, Maryland, and Virginia, experienced rotating blackouts when a generator outage occurred during the peak load period. On the worst day, July $6^{\text {th }}$, the Delmarva Power \& Light Company (DPL) implemented rotating blackouts from 10:30 AM to 7:30 PM in order to counter a capacity shortfall brought on by both high loads and multiple generation outages that could not be remedied through energy imports on the transmission system. Approximately 138,000 of DPL's customers experienced electrical outages of varying duration and frequency. One of the recommendations of the Power Outage Study Team (POST) report was remove barriers to distributed energy resources (DER), which include both distributed generation and storage $[1,2]$. The report went on to recommend support for (1) the development of interconnection standards for DER, (2) state-led efforts to address regulatory disincentives for integrating customer supply and demand solutions, and (3) the study of the potential for using emergency backup generators

This work was supported by the DER Task Force, Office of Power Technologies (OPT), U.S. Department of Energy under Contract DE-AC0500OR22725 with UT-Battelle.

R. C. Dugan is with Electrotek Concepts, Knoxville, TN 37923 USA (email: r.dugan@ieee.org). T. E. McDermott is with Electrotek Concepts, Jefferson Hills, PA USA (e-mail: temc@electrotek.com). D. T. Rizy is with the Oak Ridge National Laboratory, Oak Ridge, TN USA (e-mail: dtr@ornl.gov),

S. J. Steffel is with Conectiv, Newark DE USA (e-mail: Steve.Steffel@conectiv.com ); to reduce system demands to help avoid power outages. The U.S. Department of Energy (DOE) has formed a DER Taskforce (www.eren.doe.gov/der/), which combines all DER-related programs under the Office of Energy Efficiency and Renewable Energy (EERE) into one office. The objective of the Taskforce is to enhance the effectiveness of DOE's RD\&D, education, and implementation activities and to work with industry partners to craft a plan capitalizing on the synergy of bringing all DER programs together.

The study reported in this paper was done in part to investigate the possibility that existing backup generation could have prevented the emergency load curtailment at DPL. The capacity shortfall during the event was approximately 120 MW. A survey was conducted from which it was estimated that there is 150 to $200 \mathrm{MW}$ of backup generators installed in end-user facilities. If a substantial part of that generation could have been utilized to support the power system, it is certainly possible that the extent of the load curtailment would have been significantly reduced.

Some of this backup generation is larger 3-phase gensets in industrial facilities. However, much of this generation consists of single-phase diesel gensets for poultry houses on farms. Due to the critical need to control air temperature in the houses, each farm must have sufficient backup generation to operate the ventilation load. This backup generation is a large, underutilized resource. In the typical installation, the generator is rated greater the load so that it is able to both start the fans and serve the load continuously without difficulty. Typical generators used for this purpose are rated from 20 to $60 \mathrm{~kW}$. Some of this capacity can be realized by a simple transfer of load to the backup generation. This is already done in some installations. The question we investigated is: What are the practical limits for interconnecting the generators with the distribution system so that the remainder of their capacity can be utilized to aid the regional power delivery system?

A unique feature of this generation resource is that much of it is single-phase. While the interconnection of 3-phase generators to the utility distribution system has been investigated previously $[3,4,5]$, the peculiarities of interconnecting a large number of single-phase machines have not been investigated. This paper reports on the key findings to date of our investigation. 


\section{INTERCONNECTION ISSUES}

The primary interconnection issues for poultry farm standby generation that have been identified at this time are:

1. Voltage regulation: Farms are frequently several miles from a substation. Thus, voltage regulation will be one of the most important factors limiting the amount of generation unless special measures are taken.

2. Overcurrent Protection: Since the gensets have synchronous alternators and are connected to the system like single-phase loads, they will contribute strongly to the most common type of fault, the single-line-to-ground (SLG) fault. Thus, there is a significant chance of adverse impacts on the utility system protective relaying, requiring some operating changes to utilize the DG capacity.

3. Harmonics: Harmonics for 3-phase rotating machines are generally ignored on utility systems. However, there may be significant harmonics, particularly the third harmonic, from some single-phase alternators. Since the third harmonic is already one of the most troublesome on 4wire, multi-grounded utility distribution systems, there will be a limit to how much can be accepted from DG.

4. Islanding: Islanding is a concern because many farms are served on single-phase, fused laterals with load that is more likely to be on the same order as the machine. The fact that many of the laterals are fused is itself problematic. Compounding this are characteristics of the genset's governors and voltage regulators, which are, of necessity, more tolerant of frequency and voltage excursions than are normally expected on utility systems.

\section{EXAMPLE SYSTEM}

Figure 1 shows a one-line diagram of the example feeder chosen for this study. It is derived from an actual urban/rural 12.47-kV feeder on the Delmarva Peninsula. This feeder has several characteristics that would be considered typical of feeders serving a combination of small cities and farms in most parts of the USA. There is a bank of single-phase regulators and a 3-phase recloser in the locations indicated. The most remote part of the feeder is approximately 12 miles $(19 \mathrm{~km})$ from the substation.

A typical feeder serving poultry house loads could be expected to have 10 to 20 backup generators sized 20 to 60 $\mathrm{kW}$. For the study, the DG was assumed to be sited in 15 locations as indicated by the "G" symbol. The DG distribution was chosen randomly based on geography. Therefore, the distribution between phases was not equal. Two of the locations selected were on Phase A, five on Phase $\mathrm{B}$, and eight on Phase $\mathrm{C}$. In the base case, each generator was assumed to have a rating of $75 \mathrm{kVA}$ and to be capable of producing $60 \mathrm{~kW}$. The power output was varied for different analyses.

\section{Simulation TOOLS}

The example feeder was simulated in a software package tailored for DG applications on distribution feeders. The load flow and fault calculations were done with unbalanced phase impedance models. Note that a balanced three-phase program could not be used because of the single-phase generators and laterals. It is also important that the line voltage regulator models respond properly for power flow in both directions.

While the program can model DG with voltage dispatch (PV buses), the generators were modeled for power flow

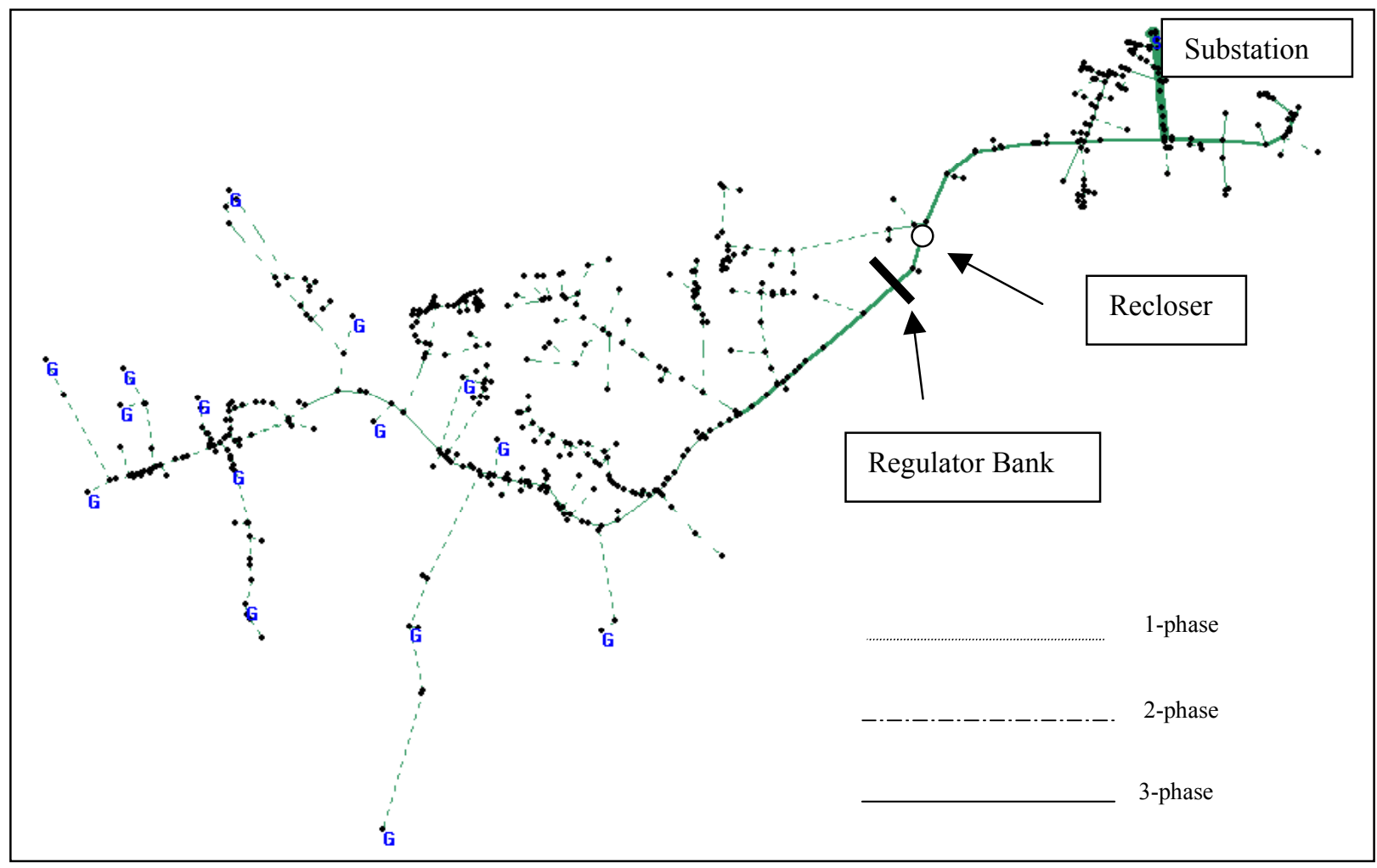

Fig. 1. One-line diagram of the utility distribution system showing assumed locations for single-phase generators. 
analysis as negative loads dispatched at constant power factor. Grid-connected DG of this type will be operated in this manner [6]. During both fault and harmonic simulations, the generators were represented as Thevenin equivalent voltages behind an appropriate impedance.

During fault conditions, the overcurrent protection device response is simulated using an event queue [7]. Each device has the time of its next state change calculated based on its current and voltage. A state change could be a fuse blowing, recloser tripping, a reclose operation, or a device reset. The program executes the earliest state change, updates the circuit topology, and then re-calculates the fault currents and voltages. The simulation of the fault stops when all protective devices have settled.

The same algorithm simulates harmonic power flow at each frequency. First, the passive component impedances are calculated at the harmonic frequency of interest. Second, each generator is represented with a harmonic voltage component (e.g., $3 \%$ of the fundamental at the $5^{\text {th }}$ harmonic), both magnitude and angle, behind a harmonic impedance. The harmonic impedance is based on the subtransient reactance adjusted for frequency. The program solves for total harmonic distortion and individual components over the spectrum.

\section{Voltage Regulation}

One of the most limiting criteria for how much DG a distribution system can support is the voltage change that occurs when the DG is suddenly connected or disconnected.

This is a case of some very practical importance. The type of DG under consideration will mostly operate as peaking generation and will be on line when the load is high. A universal requirement for DG interconnection is that it disconnect when a fault occurs so that the utility overcurrent protection system can function properly. Interconnect standards generally require DG to stay off line until the voltage has stabilized (typically 5 minutes) [6]. If the system has become too reliant on DG, the voltage will be too low when the utility breaker recloses. The regulator tap positions will be improper for operation without DG.

One must establish limiting criteria for this condition. A reasonable limit would be between $5 \%$ and $10 \%$ voltage change. If there are no voltage regulators to help correct the voltage quickly, one should choose a value toward the low end of this range. In the example circuit, there is a bank of single-phase regulators on the rural part of the three-phase feeder. Thus, an engineer might allow the maximum change $(10 \%)$ knowing that the regulator will compensate in less than one minute, if it has the proper type of control.

Figure 2 shows how the voltage at the end of the threephase feeders will change for various amounts of single-phase generators located as previously described. For a 5\% limit, a total of about $450 \mathrm{~kW}$ can be accommodated. For a $10 \%$ limit, approximately $1000 \mathrm{~kW}$ can be accommodated. This is an average of 150 and $333 \mathrm{~kW}$ per phase, respectively.

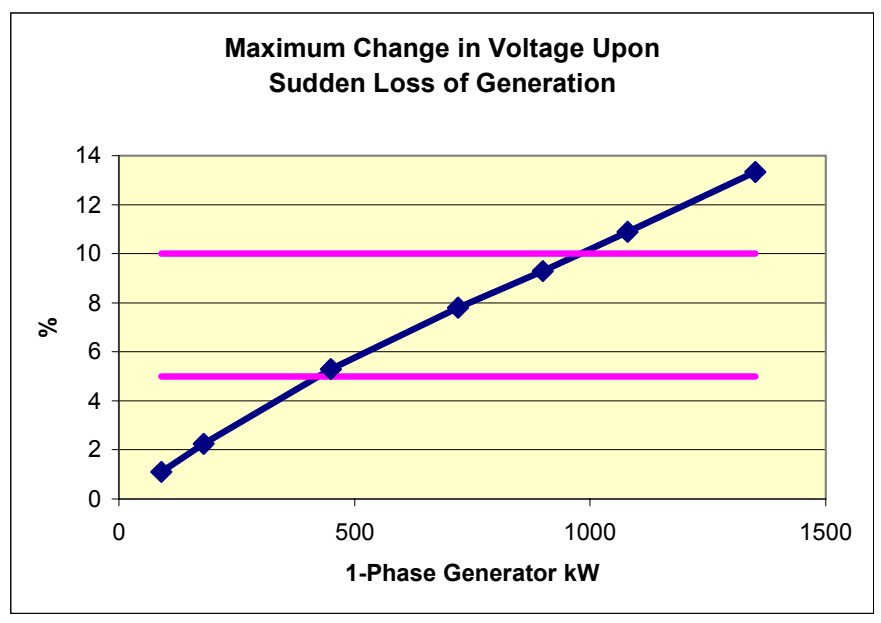

Fig. 2. Percent change in voltage at the end of the three-phase feeder upon sudden loss of generation

If the higher limit is chosen, the amount of total generation is in the range of $10 \%$ to $15 \%$ of system capacity often claimed as the maximum penetration allowable without special modifications to the utility system. If the lower design limit is chosen, the total is about half of that. One reason these limits may be lower than some might think is that we are assuming the DG is installed on the rural, single-phase extensions of the feeder. If the DG were concentrated closer to the substation, the system could accommodate more DG with respect to this voltage change consideration.

Strategies for accommodating more DG than this limit, such as more advanced regulators or restoring load in sections, are costly or would extend interruption durations.

\section{OVERCURRENT COORDINATION}

Another factor limiting the amount of single-phase DG that might be interconnected is interference with utility overcurrent protection. Single-phase generators on 4-wire, multigrounded neutral systems would be able to feed into most of the faults that occur, the most frequent being single-line-toground faults. Two common issues are discussed here.

\section{A. Interference with Fuse Saving}

Fuse saving continues to be a common practice on rural feeders. The model feeder has a 3-phase line recloser placed near the urban/rural boundary for this purpose.

Figure 3 shows a one-line equivalent for the fuse saving analysis. A 40T fuse was modeled on one of the single-phase laterals mid-way between the line recloser and the end of the 3-phase feeder. The fault was assumed to be temporary and located beyond the fuse as shown. Fuse saving requires the recloser to operate first on its fast curve. If the fault is temporary, service is restored within seconds by automatic reclosure.

This sequence was maintained until the generation capacity on the faulted phase was increased to $300 \mathrm{kVA}$. At $300 \mathrm{kVA}$, the fuse blew at the same time the recloser operated. For this DG capacity, or greater, it will be impossible to achieve fuse saving with this size of fuse. 
To accommodate more DG, the sizes of all lateral fuses in this protection zone would have to be increased. The recloser pickup current may also have to be increased to coordinate.

The delayed shot coordination of the fuse and recloser for permanent faults is actually aided by the generator infeed. In this case, proper coordination is for the fuse to melt and clear before the recloser trips.

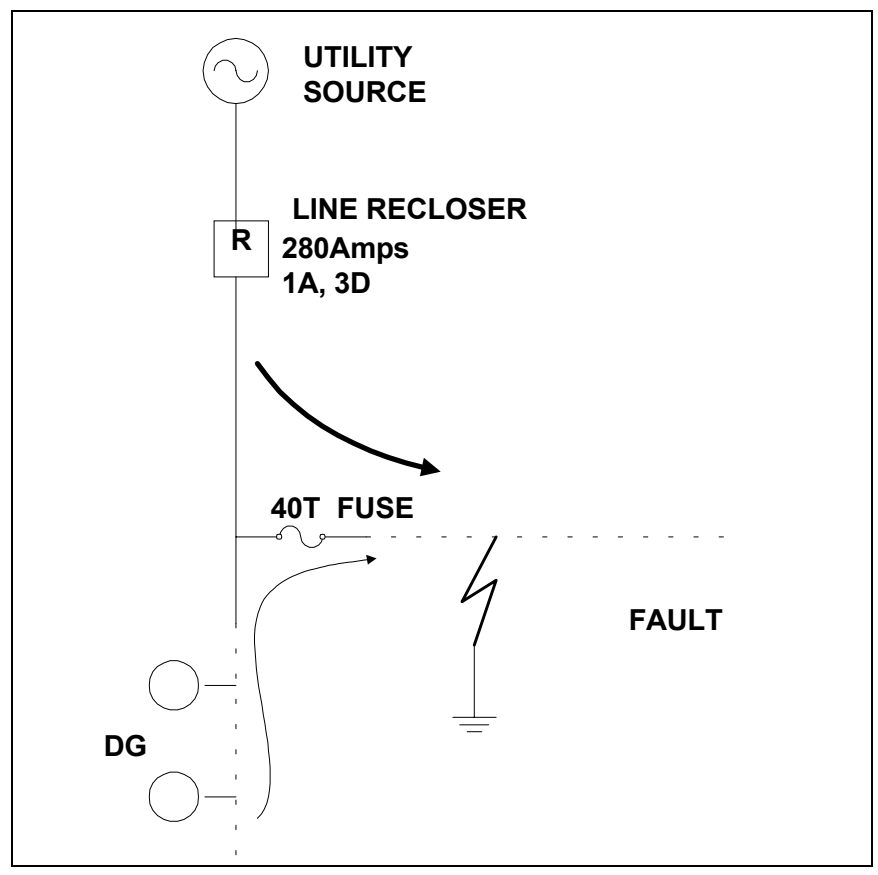

Fig. 3. Circuit for Analysis of Fuse Saving Coordination

\section{B. Reduction of Reach}

Another coordination issue is the reduction of the "reach" of overcurrent protection devices by generator infeed to faults. Reach is the term describing how far down a feeder a protective device is able to sense a fault. As shown in Figure 4 , devices in series are designed to have overlapping reaches so that there is some redundancy of protection.

The line recloser (middle of the feeder) is set to see well past the end of the feeder for the smallest fault current anticipated (highest fault resistance). If there is DG between the recloser and the fault, the current seen by the recloser is reduced, which has the following potentially harmful impacts:

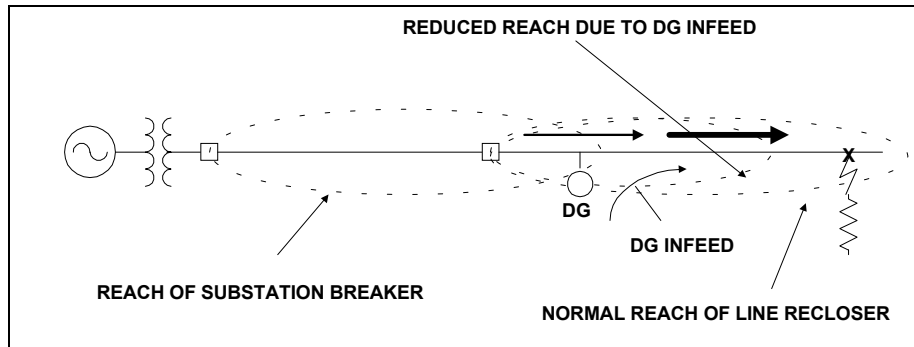

Figure 4. Circuit illustrating how DG infeed into a fault reduces the "reach" of overcurrent protective devices.

1. The fault is undetected, allowing it to burn indefinitely until the fault resistance decreases.
2. The recloser response is slowed, which allows more damage to occur or fuse saving to fail.

The impact of DG infeed was studied using the example system by setting up the condition in Figure 4. Faults of various resistances were placed at the end of the longest single-phase feeder. Fault currents were determined at peak load conditions when there is also considerable load current. This is the time the DG is likely to be connected.

At this loading, the recloser would trip for a $50-\mathrm{ohm}$ fault, which is actually quite sensitive. Since most faults would have a resistance less than this, the recloser is able to see well past the end of the feeder. As the DG size is increased, the recloser is de-sensitized. With $600 \mathrm{kVA}$ of DG on the faulted phase, the recloser in this example can only see a 20 -ohm fault, which may be satisfactory for most utility design criteria.

As the fault resistance decreases (stronger faults), there is much less impact on the reach. That is, the DG infeed will not significantly alter the coordination.

It is not entirely clear what rule can be drawn from this analysis. Even with a relatively large amount of DG, the recloser reach is probably still adequate for normal operation of the example feeder. If one were to make a design rule to see a 20 -ohm fault, $600 \mathrm{kVA}$ of DG per phase would be the upper limit. If the design called for a $40-\mathrm{ohm}$ fault, that limit would drop to $100 \mathrm{kVA}$ per phase, which is quite restrictive. Based on the reach of the recloser at no load, it would appear that the 280 -amp recloser settings are more consistent with a 20-ohm fault, which is one design value utilities commonly use. Therefore, the limit of $600 \mathrm{kVA}$ per phase is more likely to apply.

\section{HARMONICS}

Figure 5 shows the model used for the harmonics analysis. When interconnected to the utility system the bulk of the DG harmonic currents will flow into the utility system because the impedance is so much lower than the local load impedance. The generator is essentially a harmonic voltage source with the current limited by the subtransient impedance of the machine. Therefore, a Thevenin equivalent is used to model the generator.

The theory of harmonics in the machine voltage waveform is described in many textbooks, e.g. reference [8]. Information received from machine manufacturers indicates that $3^{\text {rd }}$ harmonic voltage distortion on a typical $5 / 6$ or $11 / 16$ pitch machine could be as high as $5 \%$. In addition, the $5^{\text {th }}$ harmonic is assumed to be as high as $3 \%$ and the 7 th harmonic as high as $1.5 \%$. A $2 / 3$ pitch machine is generally considered to have negligible $3^{\text {rd }}$ harmonic distortion. 


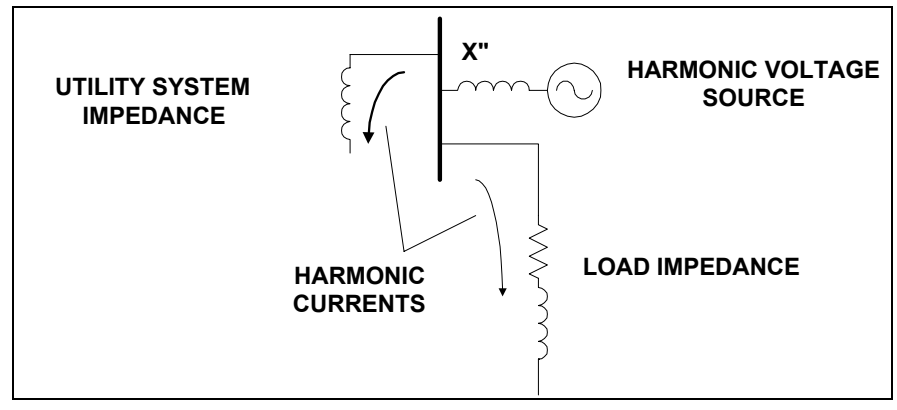

Fig.5. Equivalent circuit for harmonics analysis at the DG bus (the low voltage bus)

IEEE Std 519-1992 [9] limits the voltage distortion of a $12.47-\mathrm{kV}$ system to $5 \%$ THD (total harmonic distortion) with a maximum of $3 \%$ for any single harmonic. For the model system, the limiting factor turns out to be the $3 \%$ limit on the $3^{\text {rd }}$ harmonic voltage.

For the analysis, the size of the generators was increased until the limit was exceeded. The $3^{\text {rd }}$ harmonic voltage reaches $3 \%$ at the end of the 3 -phase feeder when there is a total of $1800 \mathrm{kVA}$ of generation in the 15 locations previously described. The limit occurs on phase $\mathrm{C}$, which has a little more than half of that generation. Therefore, this suggests a practical limit, in round numbers, of approximately $900 \mathrm{kVA}$ per phase. While somewhat restrictive, this limit is substantially more lenient than limits based on voltage regulation and overcurrent protection coordination issues.

It should be noted that IEEE Std 519-1992 allocates harmonic current limits to each load based on the capacity of the system at the point of common coupling. When the tables of allowable currents were developed, consideration was given only to loads (power consuming devices). The developers of the standards have indicated to the authors that the available harmonic capacity was allocated to loads and there is no capacity remaining for DG devices. Thus, DG is subjected to the most strict current injection limits in the standard as if it were on a very weak system.

Despite this, it does not appear that harmonics will be the limiting factor in the application of single-phase backup DG to utility distributing systems. Nuisance problems may still occur. Since the resulting harmonic currents will flow in the local farm and the utility grounding systems, there may be some stray voltage problems, which is a sensitive issue for farms. The impedance of the system to the $3^{\text {rd }}$ harmonic will be higher than for the fundamental frequency, so it may require more diligence to get a suitable grounding system.

Another issue may be increased telephone interference while the DG is operating. Due to the presence of harmonic currents where there were none previously, weaknesses in the shielding of the telephone system may be exposed.

\section{VIII.ISLANDING}

Utilities are always concerned with the formation of unwanted islands in the system when DG is present. The main concerns are safety of the work crews and the public as well as damage to load equipment for which the utility might be held liable.

The probability of islanding is generally considered to be small. It requires a very well-balanced match between load and generation - both watts and vars - to escape detection. However, most previous studies have been done assuming three-phase systems on which the load in a likely island is much greater than the proposed generation. One aspect that is different about single-phase generation is that many will be served from fused single-phase laterals (Figure 6). The load on the lateral is more likely to be within the DG capacity. Also, there are potentially a large number of sites. Therefore, without specific islanding protection, the probability of a single-phase farm generator somewhere on the system supporting an island should be higher than for 3-phase gensets based on sheer numbers of installations.

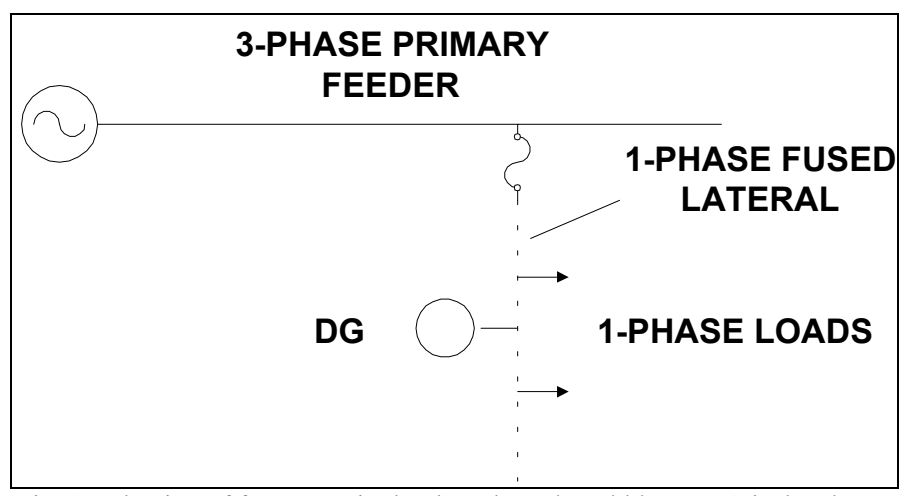

Fig. 6. Blowing of fuse on a single-phase lateral could leave DG isolated on a relatively small amount of load, increasing the likelihood of unintentional islanding.

The root cause of the increased concern for islanding is the lateral fuse. In some interconnection standards for threephase generation, there are recommendations for not using line fusing or single-phase reclosers between the substation and the generator. The concern for three-phase generators is with single-phasing the generator. If protection is required, a three-phase line recloser is often used. The concern with line fuses for a single-phase generator is that it makes it easier for islanding to occur.

There are several scenarios under which the single-phase lateral fuse might blow and isolate the DG on the lateral. Two common ones are:

1. A fault occurs near the fuse, which blows quickly. This can happen as fast as 1-2 cycles. It is not uncommon for a fuse to melt and clear in a half cycle. The islanding detection at the DG may interpret this as a brief voltage sag caused by a fault on another feeder that has been cleared. Thus, the DG stays connected.

2. A fuse weakened by age and previous temporary faults blows on load current at peak load when the generator is running. This might be triggered by starting a large motor on one of the farms served from the lateral. 
One solution is to replace the fused cutouts with solid blades on laterals with DG. A fault will result in the operation of the next upline protection device, which would isolate the DG with an amount of load that it is very unlikely of being able to support. Of course, this would be detrimental to the overall reliability of the distribution system. Single-phase laterals are fused to prevent permanent faults on the often lengthy laterals from causing sustained interruptions of the main three-phase feeder. Thus, eliminating the fuse will diminish the reliability for other parts of the feeder.

Eliminating the fuse runs counter to recommendations for improving the reliability of the distribution system. This is one illustration of the potential conflicts between local and regional reliability requirements. The DG would be used at peak load to support the regional power delivery system, in this case the transmission system on the Delmarva Peninsula. However, this may require sacrificing reliability in some areas of the distribution system in order to permit the interconnection of the DG.

\section{CONCLUSIONS}

Our study of a typical feeder representative of the Delmarva Peninsula service territory has explored the use of grid connected backup emergency gensets to provide DG to the utility system. We have evaluated interconnection issues for single-phase standby generators like those typically found on poultry farms, including voltage regulation, overcurrent protection, harmonics, and islanding.

The two issues placing the most restrictive limits on the amount of single-phase gensets that can be accommodated without making changes to the distribution system are

1. The voltage drop when the DG disconnects for fault clearing, and

2. Fuse saving coordination.

Table I lists the various criteria and the associated limits.

TABLE I

LIMITS FOR SINGLE-PHASE GENERATORS (ROTATING MACHINES) ON A RURAL 12.47 KV DISTRIBUTION FEEDER

\begin{tabular}{|l|l|}
\hline \multicolumn{1}{|c|}{ Criterion } & \multicolumn{1}{c|}{ Limit } \\
\hline $5 \%$ Voltage Drop & $150 \mathrm{kVA}$ per phase \\
\hline $10 \%$ Voltage Drop & $333 \mathrm{kVA}$ per phase \\
\hline Fuse Saving, 40T Fuse & $300 \mathrm{kVA}$ per phase \\
\hline 20 -Ohm Fault Detected & $600 \mathrm{kVA}$ per phase \\
\hline $3 \% 3^{\text {rd }}$-harmonic voltage & $900 \mathrm{kVA}$ per phase \\
\hline
\end{tabular}

We expect that similar results would be obtained for other rural feeders. If one were to generalize these results to come up with approximate estimating numbers for an initial screening of the amount of DG that could be accommodated without making changes to the distribution system, we would suggest the following limits:

1. $300 \mathrm{kVA}$ per phase if there is a suitable, fast acting voltage regulator on the line, or

\section{2. $150 \mathrm{kVA}$ per phase, if no suitable regulator.}

Stated in terms of percent of total feeder capacity, these limits correspond to approximately $10 \%$ and $5 \%$, respectively. This is lower than the typical limits for 3-phase machines, primarily because of the assumed distance from the substation. If the total DG exceeds these limits, additional study might be required.

It is technically feasible to accommodate more generation of this type, but changes to the distribution system will likely be necessary. These changes will have an associated cost either in terms of actual hardware and labor to solve a problem, or in reliability impacts on other customers. For example, if fuses are removed to prevent islanding, the rest of the feeder will be exposed to more momentary and sustained interruptions due to faults on the single-phase laterals. If fuse saving is abandoned, customers on the fused laterals will see an increase in sustained interruptions.

\section{REFERENCES}

[1] Report of the U.S. Department of Energy's Power Outage Study Team; Findings and Recommendations to Enhance Reliability from the Summer of 1999, U.S. Department of Energy, March 2000 (www.eren.doe.gov/der/chp/doclibrary.html).

[2] Making Connections, Case Studies of interconnection Barriers and their Impact on Distributed Power Projects, NREL/ SR-200-28053, May 2000, (www.eren.doe.gov/distributedpower/barriersreport/)

[3] R. D. Richardson, R., C. Dugan, and G. J. Ball, "Engineering handbook for dispersed energy systems on utility distribution systems", EPRI, Palo Alto, CA, Report TR-105589, Nov. 1995.

[4] P. P. Barker et. al., "Integration of distributed resources in electric utility systems: current interconnection practice and unified approach," EPRI, Palo Alto, CA, Report TR-111489, Nov. 1998.

[5] R. C. Dugan and T. E. McDermott, "Operating Conflicts for Distributed Generation on Distribution Systems," Presented at 2001 IEEE IAS Rural Electric Power Conference, Little Rock, AR, May 2001.

[6] IEEE Standard for Distributed Resources Interconnected with Electric Power Systems, IEEE Standard P1547/D07 (draft), February 2001.

[7] T. E. McDermott, R. C. Dugan, and G. J. Ball, "A methodology for Including power quality concerns in distribution planning", presented at the 5th International Conference on Electrical Power Quality and Utilisation (EPQU 99), September 15-19, 1999, Cracow, Poland.

[8] G. McPherson, R. Laramore, An Introduction to Electrical Machines and Transformers, John Wiley \& Sons, New York, 1990, Chap. 2.

[9] IEEE Recommended Practice and Requirements for Harmonic Control in Electric Power Systems, IEEE Standard 519-1992.

\section{BIOGRAPHIES}

Roger C. Dugan (F '00) has been Sr. Consultant with Electrotek Concepts, Knoxville, TN, since 1992. He is a graduate of Ohio University and RPI, Troy, NY. He was previously employed by Cooper Power Systems for 19 years.

Thomas E. McDermott (SM '90) is Project Engineer with Electrotek Concepts, Jefferson Hills, PA. He is also a graduate of RPI and earned his Ph. D. in distribution engineering from Virginia Tech in 1998.

D. Tom Rizy (SM'87) has been a researcher and project manager in the Power Systems Research Group, Energy Division, at the Oak Ridge National Laboratory (ORNL), Oak Ridge, TN since 1978. He is a graduate of the University of Virginia, Charlottesville, VA and Virginia Tech, Blacksburg, VA.

Stephen J. Steffel is Senior Project Engineer with Conectiv in Newark, DE. $\mathrm{He}$ is responsible for planning major capital upgrades to the distribution system and actively evaluates DG as an alternative. 